Boise State University

ScholarWorks

Civil Engineering Faculty Publications and

Presentations

Department of Civil Engineering

6-1-2017

\title{
Target Reliability Approach to Study the Effect of Fiber Reinforcement on UCS Behavior of Lime Treated Semi-Arid Soil
}

\author{
Arif Ali Baig Moghal \\ King Saud University \\ Bhaskar C.S. Chittoori \\ Boise State University \\ B. Munwar Basha \\ IIT Hyderabad \\ Mosleh Ali Al-Shamrani \\ King Saud University
}




\title{
Target Reliability Approach to Study the Effect of Fiber Reinforcement on UCS Behavior of Lime Treated Semi-Arid Soil
}

\author{
Arif Ali Baig Moghal, Ph.D., M. ASCE* \\ Associate Professor,and Bugshan Research Chair in Expansive Soils, \\ King Saud University \\ Riyadh, Saudi Arabia \\ reach2arif@gmail.com \\ Bhaskar C. S. Chittoori, Ph.D., P.E., M. ASCE \\ Assistant Professor \\ Boise State University \\ Boise, ID \\ B. Munwar Basha, Ph.D., M. ASCE \\ Assistant Professor \\ IIT Hyderabad \\ Kandi, Sangareddy, Telangana, India \\ Mosleh Ali Al-Shamrani, Ph.D. \\ Professor and Director Bugshan Research Chair in Expansive Soils, \\ King Saud University \\ Riyadh, Saudi Arabia
}

\begin{abstract}
This paper evaluates the effectiveness of stabilizing expansive soil with two different types of fibers, Fiber Mesh ${ }^{\circledR}(\mathrm{FM})$ and Fiber Cast ${ }^{\circledR}(\mathrm{FC})$, in conjunction with chemical stabilization. The intention of this study is to evaluate the effect of these fibers and lime in stabilizing expansive soil by improving its UCS behavior. The effect of varying lengths $(6 \mathrm{~mm}$ and $12 \mathrm{~mm})$ and amounts $(0.2,0.4$ and $0.6 \%$ dosage by weight of soil) of FC and FM fibers and curing periods $(0,7,28,60,120,180$ and 360 days) on the UCS and on secant modulus of a semi-arid expansive soil, in the presence of lime, was investigated. The main focus of this paper is on the determination of optimum fiber reinforcement parameters (in terms of fiber type, length and dosage) for the stabilization of expansive soil in terms of UCS, which is of a prime importance in soil stabilization projects for practicing engineers. In deterministic optimization, the uncertainties associated with subgrade soil of the pavement system are not explicitly taken into account. Hence, resulting optimal solutions may lead to reduced reliability levels of the pavement. Therefore, this paper also focuses on determining the optimum amounts of reinforcement for desired UCS performance of lime blended expansive soil using target reliability approach (TRA). The experimental data was used to develop a parabolic model using factors such as, length and dosage of fiber types to predict UCS as a response variable. In addition, it was concluded that the TRA can be successfully employed in expansive soil stabilization applications in determining the optimum length and dosage of fiber reinforcements.
\end{abstract}

CE Database Subject Headings: expansive soils, lime, fiber, unconfined compressive strength, secant modulus, reliability 


\section{Introduction and Background}

Expansive soils cause millions of dollars of damage each year due to their swell/shrink behavior during moisture ingress and digress. A study (Jones and Holtz, 1973) sponsored by the National Science Foundation (NSF) reported that the damage to structures caused by expansive soils - particularly to light buildings and pavements - is more than any other natural disaster, including earthquakes and floods. Through a detailed review of expansive soils, Gromko (1974) estimated that the annual cost of damage from these soils in the United States alone is \$2.3 billion. Vanapalli and Adem (2013) reported the annual cost of damage to structures constructed on/with expansive soils for various regions of the world.

Petry and Armstrong (1989) noted that it was more economical to perform initial stabilization of these soils before/during construction of the overlying structures rather than performing remedial treatments later on with existing structures around. Chemical stabilization of expansive soils has been a very stable and efficient solution in the short term. However, long-term durability of these methods are unpredictable and depends on the mineralogy of soil, environmental conditions such as availability of water and construction methods (Chittoori et al., 2009; Chittoori et al., 2014). Chemical stabilization certainly makes these soils strong in compression, but it contributes very little in tension. This becomes a major problem in summer seasons when the soils are expected to refrain against tensile cracking.

A natural method to strengthen any material in tension is providing reinforcement. The use of randomly mixed synthetic fibers is a viable option in improving the tensile strength of soils. Relying on fiber reinforcement method, which is cost effective and eco-friendly requiring minimal machinery, several diverse materials can be used to reinforce majority of soils. However, durability could be an issue when natural fibers (palm and jute fibers) are employed as they offer improvement on only short term basis and are beneficial for only shallow depths (Babu and Vasudevan 2008, Anggraini et al. 2015, Qu and Zhao 2016).

In order to circumvent the durability issue, synthetic polypropylene fibers having durable life span were used (Consoli et al. 2011, Correia et al. 2015). The wealth of earlier available literature suggests that both fiber characteristics (including fiber orientation, type, length, thickness, dosage and geometry), nature of clay and type of stabilizer affect the resultant behavior of fiber-reinforced clays (Gray 1970, Gray and Maher 1989; Maher and Ho 1994; Consoli et al. 2009; Ahmed et al. 2010; Zhu et al. 2014; Tang et al. 2016). Past studies performed to assess the benefits of using synthetic fibers in conjunction with chemical stabilization are discussed in the following sections.

Kumar et al. (2006) studied the compressive strength of compressible clay upon plain and crimped polyester fiber inclusion. The dosages of fibers were maintained at $0.5,1,1.5$ and $2 \%$. The results indicated that the unconfined compressive strength (UCS) increased with the addition of fibers and it depended on the degree of compaction. Consoli et al. (2010) studied the effect of fiber-reinforcement (monofilament polypropylene fibers) on the UCS of cemented soils. The fibers used in this study were $24 \mathrm{~mm}$ long and $0.023 \mathrm{~mm}$ in diameter, with a specific gravity of 0.91 , tensile strength of $120 \mathrm{MPa}$, elastic modulus of $3 \mathrm{GPa}$. The various controlling parameters included cement, porosity, moisture content and void/cement ratio. The study revealed that, for the whole range of cement tested, the addition of fiber resulted in an increase in UCS for both fiber reinforced as well as unreinforced specimens. In an another extended study by Consoli et al. (2011), on the same fiber material, at varying fiber contents of $0,0.25,0.50$, and $0.75 \%$ by weight of the sum of dry soil and cement, it was observed that for a given fiber content, the UCS, $\mathrm{q}_{\mathrm{u}}$ is dependent on both the porosity and the cement content of the mixture. Increasing values of porosity results in reduction in $\mathrm{q}_{\mathrm{u}}$, whereas increasing values of cement content results in larger values of $\mathrm{q}_{\mathrm{u}}$ obeying an explicit relation between $\mathrm{q}_{\mathrm{u}}$ and cement/porosity ratio $\left(\mathrm{C}_{\mathrm{iv}}=\eta\right)$.

Another study by Tang and Shi (2007) showed that the inclusion of fiber reinforcement within uncemented and cemented soil caused an increase in the UCS, shear strength and axial strain at failure. Increasing fiber content could increase the peak axial stress and decrease the stiffness, and the loss of post-peak strength weakens the brittle behavior of cemented soil. The increase in strength of combined fiber and cement inclusions is much larger than the sum of the increase caused by the inclusion of either one individually. The "bridge" effect of fiber efficiently impeded the further development of tension cracks and deformations in the soil. Bond strength and friction at the interface seem to be the dominant mechanisms controlling the reinforcement benefit. In fiber-reinforced uncemented soil, interactions occur at the interface between the fiber surface and the clay grains that play key role in the mechanical behavior. 
Marandi et al. (2008) used natural palm fibers as soil reinforcement. Fiber contents used were $0.25 \%, 0.50 \%, 0.75 \%$, $1.00 \%, 1.5 \%, 2.00 \%$ and $2.50 \%$ by dry total weight whereas the fiber lengths tested were $20 \mathrm{~mm}$ and $40 \mathrm{~mm}$. The results showed that the stress-strain behavior was markedly affected by the palm fiber inclusions. In specimens without palm fibers; a distinct failure axial stress was reached at an axial strain of approximately $1.23 \%$. Whereas, the palm fiber reinforced specimens while exhibiting a more ductile behavior showed that at a constant palm fiber length $\left(\mathrm{L}_{\mathrm{f}}\right)$, with increase in fiber inclusion $\left(\mathrm{W}_{\mathrm{f}}\right)$, the maximum strength and residual strength increased, while the difference between the two decreased. Increasing fiber length while maintaining constant fiber inclusion, both maximum and residual strengths of the specimens increased. It is evident based on the above results that, in reinforced soils, where the soil grains are replaced by fibers, it is the fibers that control the behavior of the specimen.

Cai and Shi (2006) studied the use of lime and fibers on six different soil samples at different combinations of lime and fiber contents. They observed that with an increase in fiber content, the compressive strength of samples increased. In the case of equal fiber or lime content, fiber-lime soils experienced a more notable increase in the UCS than either lime-treated soil or fiber reinforced soils. The prominent improvement of fiber-lime soils in compressive strength is due to the combined action of lime and fiber. On one hand, the reactions between lime and clayey particles changed the natures of soils and consequently improved the strength of soils. On the other hand, the development of friction between fiber and soil particles confined the lateral deformation of specimens and hence increased the compressive strength.

This paper focusses on evaluating the strength performance of lime stabilized expansive soils in the presence of randomly mixed synthetic polypropylene fibers. In the presence of lime, the effect of various fiber parameters including nature and type of fiber, fiber length and fiber dosage on the UCS behavior and secant moduli values has been evaluated. Further, relying on target reliability criteria, two parabolic equations are proposed for computing the UCS of treated and fiber reinforced expansive soils using the dosage and length of fiber reinforcement. This study is perhaps the first to propose the optimum dosage and length of the fiber reinforcement required to maintain the stability against UCS strength failure by targeting various reliability indices.

\section{Materials and Methods}

Soil from Al-Ghat region (located $270 \mathrm{~km}$ Northwest of Riyadh (26 32' 42" N, 43 45' 42" E)) of Saudi Arabia was selected for this research. Sampling was carried out at a depth of $3 \mathrm{~m}$ from the surface. The physio-chemical properties of this soil are reported in Table 1. Physical properties included Atterberg limits, sieve analysis, hydrometer tests, specific gravity and specific surface area, as given in Table 1 . The soil is classified as high plasticity clay as per the Unified Soil Classification System. The chemical composition presented in Table 1 was determined using wavelengthdispersive $\mathrm{x}$-ray fluorescence spectrometry (XRF). The soil is rich in both alumina and silica phases which is a prime requirement for chemical stabilization. This soil was stabilized with $6 \%$ quick lime as determined from earlier studies performed on these soils based on response to soil $\mathrm{pH}$, initial lime consumption values and lime leachability criteria (Eades and Grim 1960; Moghal et al. 2015a, 2015b, 2015c).

Two types of fibers were studied in this research, the FIBERCAST® 500 (FC) and FIBERMESH® 300 (FM) (Fig. 1). These fibers were obtained from Propex operating company, LLC, United Kingdom and their physio-chemical properties are given in Table 2. Fig. 1 depicts the surface profiles of these fiber materials relying on scanning electron microscope. It can be seen that the surface of FC is relatively smooth and represents parallel smooth strings while FM has a rough surface with protrusions (branching extrusions).

\section{Unconfined Compressive Strength Test}

Soil samples prepared for this research were subjected to UCS testing as per ASTM D 2166M-13 (2013). Soil samples for UCS tests (38mm in diameter and $76 \mathrm{~mm}$ in length) were prepared by compacting the samples at maximum dry unit weight and optimum moisture content obtained from standard proctor test as per ASTM D698-07e1 (2007) for varying fiber dosages and fiber types. Initially, samples were prepared by mixing the fibers into dry soil and compacting the mixture at optimum moisture content (OMC) and maximum dry density (MDD) corresponding to that particular mix. The OMC and MDD for each mix were obtained by performing standard proctor tests in accordance with ASTM D698-07e1 (2007). These results are presented in Table 3. The prepared samples at respective maximum dry density and moisture content values were tested as per ASTM D2166M-13(2013) relying on static compaction technique. The specimen was then loaded on the compression device and sheared at a strain rate of $0.05 \mathrm{~mm} / \mathrm{min}$ as 
per ASTM D2166M-13 (2013). For lime treated samples, similar procedure was followed except that the lime was added to dry soil before mixing with the fibers. From the stress strain curves, the magnitudes of the stress and the strain values corresponding to peak stress were noted.

In order to study the effect of curing on the UCS behavior, the compacted soil samples were wrapped in plastic wraps with the help of adhesive tape and preserved in a $100 \%$ humidity room to ensure that there are no moisture movements from or into the sample, and cured for 1, 7, 28, 60, 120, 180 and 360 days. At the end of any given curing period, the weight of the specimen to be tested was determined and compared with its original weight. The specimens that lost more than $5 \%$ of its weight due to heat of hydration (due to lime addition), were rejected. Further, the samples whose diameter deviated by more than $\pm 0.5 \mathrm{~mm}$ and length by more than $\pm 1 \mathrm{~mm}$ were discarded and the samples whose dry density to degree of compaction ratio was falling outside the range of 99 to $101 \%$ were discarded. In order to ensure repeatability and reproducibility, all data points reported here are the average of a minimum of two tests, and in cases where two tests did not agree a third test was performed and the three values were averaged.

The effect of parameters such as length and amount of fibers on the strength characteristics of expansive soils was explored in this research. Further, secant modulus values at $50 \%$ of peak strength were determined from stress-strain curves.

\section{Analysis of Test Results}

UCS tests were performed on both untreated and treated soils. The untreated UCS values for Al-Ghat soil was 589.1 $\mathrm{kPa}$. The amount of fibers used were $0.2 \%, 0.4 \%$ and $0.6 \%$ by dry weight of the untreated soil while the length of fibers was fixed at $6 \mathrm{~mm}$ and $12 \mathrm{~mm}$. In addition, the effect of curing time on strength improvement was examined considering curing periods of 7, 28, 60,120, 180 and 360 days. It is quite common to study curing periods of 7 and 28; however, in this study extended curing periods were considered to establish the length of time beyond which no additional strength gain is possible.

\section{Unconfined Compressive Strength (UCS) Behavior}

\section{Effect of Curing Period}

Fig. 2 presents the variation of UCS values with curing period for various fiber dosages and lengths using FC and FM, respectively. It was observed that the combined addition of lime and fiber has a significant effect on the rate of gain of UCS. It should also be noted that the UCS values increased with curing periods up to 60 days and relatively stayed constant after that. Similar observations were reported by Tang et al. 2007 for clayey soils reinforced with short polypropylene fibers in the presence of cement.

Prima facie, it appears that up to 60 days curing period, the release of reactive silica and alumina from inert clay phase proceeds without any hindrance owing to smooth solubility of silica. At higher curing periods (above 60 days), the readily available reactive silica is consumed and the $\mathrm{pH}$ of the resultant soil-system drops inhibiting any further release of amorphous reactive silica (Moghal et al. 2014). Further, the addition of fibers disturbs the alteration of water film surrounding the clay minerals and does not allow the pozzolanic materials to progress after reaching equilibrium levels (in this study equilibrium levels can be taken as 60 days). Accordingly, the rate of gain in UCS at higher curing periods proceeds at a slower rate (Fig. 2).

From Table 3, for any given fiber length, the density reduced with the increase in fiber dosage, with a corresponding increase in optimum moisture content values. The same is true for increase in fiber length. With increase in curing periods, at higher densities (prevailing at lower fiber dosage levels i.e., at $0.2 \%$ ) relatively greater contact points are established between pozzolanic compounds formed due to addition of lime (in the form of calcium aluminium hydrate and calcium aluminium silicate), and the clay particles and the fiber material, which assist the increase in UCS values (Consoli et al. 2013, Moghal et al. 2014).

\section{Effect of Length and Amount of Fiber}

Fig. 3 demonstrates the effect of the amount and length of fiber on the UCS values for the selected soil. It can be observed that in case of FC fiber as the amount of fibers increased from $0.2 \%$ to $0.6 \%$ the UCS values reduced by $32 \%$ and $39 \%$ for $6 \mathrm{~mm}$ and $12 \mathrm{~mm}$ lengths, respectively. This reduction is due to the fact that smooth textured fibers 
(FC) (Fig. 1) do not allow the soil to compact up on reinforcement. In addition, the fibers reduce the cohesion of the soil by increasing the distance between particles. The increase in friction induced by the smooth FC fibers does not compensate this loss in cohesion.

On the contrary, in case of FM fiber, for a similar change in fiber amount, the UCS values for samples mixed with 6 $\mathrm{mm}$ fiber length reduced by $30 \%$ while those of $12 \mathrm{~mm}$ fiber lengths showed an increase of $12 \%$. The reduction in strength with increase in case of FC compared to FM is predominantly due to difference in the respective surface morphological properties as seen from Fig. 1. The surface of FC is relatively smooth compared to that of FM with elongated protrusions enabling greater mobilization of friction levels. The rate of increase in UCS values with increase in fiber length for FM fiber is only marginal $12 \%$, which reinforces the fact that, higher dosage of shorter fibers is preferred over longer fibers. This is in agreement with the findings of Consoli et al. 2011, wherein the authors claim that for cement treated fiber reinforced soils, the adjusted cement/porosity ratio does not depend heavily on the fiber content.

\section{Secant Modulus Behavior}

The elastic moduli are important parameters required for the behavioral analysis of substructures and aid in the calculation of the elastic deformation experienced by soils when subjected to static loads. Similar to the UCS test data, the effect of random fiber reinforcement on the stiffness of the soil is also analyzed. To study the stiffness behavior with treatments, secant moduli (defined as the slope of the line joining the origin to a point corresponding to 50\% of peak axial stress in a typical stress-strain curve) were determined relying on the stress-strain curves obtained for the USC tests. The following sections present this analysis.

\section{Effect of Curing Period}

For lime-stabilized fiber reinforced soils, both strength and stiffness are key design parameters and their growth is time dependent. Fig. 4 presents the variation of secant modulus values with curing period for various fiber dosages and lengths using FC and FM, respectively. The dotted lines represent $6 \mathrm{~mm}$ long fibers with different dosage amounts while the solids lines represent $12 \mathrm{~mm}$ long fibers with different dosages. It can be observed from Fig. 4 that the secant modulus values increased with curing periods up to 60 days and stayed approximately constant until 180 days and this increase is proportional to the increase in UCS values (Fig's 2 and 3).

Up to 180 days, the amorphous nature of pozzolanic compounds formed allows the samples to endure higher strain levels, which resulted in proportional increase in secant modulus values on par with UCS values. The secant modulus values increased considerably for the 360 day cured samples for all mixes, irrespective of the type (i.e. FC and FM) and length (i.e. $6 \mathrm{~mm}$ or $12 \mathrm{~mm}$ ) of fiber. This is attributed to the transformation of amorphous pozzolanic compounds to crystalline form, which endure relatively lower strain levels even at higher peak stress levels as seen from Fig's 2 and 3 (Sivapullaiah and Moghal 2011, Moghal et al. 2014). Relatively higher secant moduli are noticed for FC fibers compared to FM type. This is attributed to higher friction mobilization in FM type along with crystallization of pozzolanic compounds which makes the sample more brittle compared to FC type where these friction mobilization levels are low owing to smooth morphological texture features (Fig. 1).

\section{Effect of Length and Amount of Fiber}

Fig. 5 presents the effect of fiber dosage on the secant modulus of soil for both FC and FM type fibers. It can be seen that for FC type fibers $(6 \mathrm{~mm}$ and $12 \mathrm{~mm})$, the rate of increase in secant moduli values compared to untreated soil, reduced with increase in fiber dosage. This reduction is much higher in FM type fibers compared to FC type fibers. In fact, FM fibers owing to their distinct surface morphological properties (Fig. 1) endure higher peak stress values at lower strain levels compared to FC fibers and this drastically affects their secant modulus values. Further, this effect is more pronounced for shorter $6 \mathrm{~mm}$ fibers compared to longer $12 \mathrm{~mm}$ fibers with increase in dosage levels for FM type fibers as seen from Fig. 5. 


\section{Necessity for Reliability Based Design}

Constructing pavements on expansive soils can result in economic loss (Petry and Little 2002), whereas pavements on lime blended expansive soils (National Lime Association, 2004), stabilized with fiber reinforcement (Cai et al. 2006), would result in overly expensive systems. Pavements constructed on reinforced subgrades have several advantages from economic, environmental and traffic safety point of view (Marandi et al. 2008). It allows thinner road structures and prolonged life cycles, which lead to a saving in natural resources. The purpose of stabilizing the expansive subgrades is to reduce rutting, differential and total settlement, maintenance costs and reflective cracking. Moreover, it increases the pavement fatigue life and bearing capacity (Ozkul and Baykal 2006). The estimates of UCS of stabilized soils are widely used in pavement engineering, yet uncertainty in UCS poses a critical design challenge. This uncertainty stems from natural variability due to numerous factors, which are discussed in the following section.

\section{Factors Affecting the Variability Associated with UCS}

Expansive soils can be stabilized by mixing discrete fibers randomly with subgrade soils. The randomly distributed fiber as reinforcement limit the potential planes of weakness that can develop parallel to oriented reinforcement. The influence of randomly oriented fibers on the mechanical and dynamic properties of fine grained soils has been reported by Maher and Ho (1994), Nataraj and McManis (1997), Cai et al. (2006), Ozkul and Baykal (2006) and Tang et al. (2007). Moreover, it is essential to realize that the degradation of synthetic fiber reinforcements which occurs with time (aging) depends on numerous factors such as the specific fiber, configuration of the fiber reinforcements, the environment to which they are exposed, saturation due to percolation of water, the level of stress to which they are subjected, exposure to construction stresses, leaching and/or biological attack of additives and stabilizers that improve the resistance of the basic polymer (Abu-Sharkh and Hamid 2004). These factors reduce the frictional resistance between fibers and soil particles and tensile strength of the fiber reinforcement over the period of time. Consequently, the UCS of the subgrade soil is greatly affected. It is therefore important to realize that there is a high degree of variability associated with UCS, and hence it is essential to evaluate the safety of pavements with suitable approaches that considers variability and uncertainty in a rational way.

\section{$\underline{\text { Traditional Design versus Reliability Based Designs }}$}

The uncertainty associated with UCS can be dealt with subjectively, relying on conservative value of lime-blendedfiber-reinforced expansive soil. However, the selection of an over-conservative UCS value can have a negative impact on both the project cost and schedule. Given the potential for variable strength behavior, the pavement engineer is faced with a critical issue: how to design a pavement system that will be stable over the range of possible UCS values? To simplify this problem, uncertainty is typically dealt with subjectively through the selection of a single set of UCS values. Conservative UCS values are most often used, resulting in the selection of a thicker pavement section. This approach may produce a robust design to withstand a range of possible loading conditions. However, this approach is not only uneconomical but also inadequate to account for the uncertainty associated with UCS parameter. This leads to a lack of awareness of the likelihood of undesirable pavement performances that can result in rutting and fatigue. In view of this, reliability methods offer an alternative approach that focuses on quantifying the uncertainty in UCS values and utilizing it directly in the design process. Reliability based design optimization (RBDO) methods, when used in conjunction with more deterministic design approaches, provide a possible solution.

\section{$\underline{\text { Studies Pertaining to Reliability Assessment Based on UCS }}$}

AASHTO (1993) reported a reliability based design of flexible pavements. Sani et al. (2014) illustrated the methodology for the reliability analysis of treated black cotton soil using cement kiln dust for strength characteristics including UCS, California bearing ratio and resistance to loss in strength using first order reliability method. It is important to note that a limited number of studies have been carried out on reliability analysis of fiber-reinforced expansive soils.

\section{Objectives and Scope of the Reliability Analysis}

Efforts have been made in the present paper to address the effects of variability associated with UCS and characteristics of fiber reinforcement (type, length and dosage) on subgrade strength failure. Two parabolic equations are proposed for computing the UCS of treated and fiber reinforced expansive soils using the dosage and length of 
fiber reinforcement. Attempts have been made to develop a framework for target reliability approach (TRA) for ensuring adequate safety against compressive strength failure of treated expansive subgrade material. The present study proposes optimum dosage and lengths of fiber reinforcement required to maintain stability against UCS failure by targeting various reliability indices.

\section{Development of Target Reliability Approach (TRA)}

A reliability analysis is performed to further validate the experimental data and account for the variability in UCS due to inherent material variability, changes in testing conditions and operator dependence. A regression equation is developed that correlates UCS values with material variables such as length and dosage. The performance functions are established using codal provisions for pavement applications. Probabilistic design optimization of pavement subgrade material enables designers to quantitatively take into account the uncertainties associated with the UCS of the fiber reinforced expansive soil, length and dosage of fiber reinforcement. Basha and Babu (2010,2012) showed that the TRA is inherently robust and yields a higher overall RBDO rate of convergence when compared to a conventional first order reliability method (FORM) approach. Hence, the TRA procedure is used herein for the reliability analysis. The TRA is concerned with finding the mean values of length and dosage of synthetic FC and FM reinforcement such that a prescribed performance function is optimized while ensuring that the strength of subgrade material is within acceptable limits. The basis for TRA is similar to theoretical background of FORM. In the following sections, statistical analysis of experimental data, calculation of the reliability index using the TRA are described.

\section{$\underline{\text { Development of Regression Model }}$}

The influence of length and dosage of both fibers on UCS values were expressed through a nonlinear regression equation, which is based on the experimental data measured after 28 and 360 days curing periods in the present study. The parabolic models were chosen as they better represent UCS data (i.e. six data points) obtained from laboratory tests (Archontoulis \& Miguez 2015). The parabolic equation adopted for the regression analysis is expressed as:

$$
U C S_{F i t}=\mathrm{a}+\mathrm{b}\left(\mathrm{L}_{F}\right)+\mathrm{c}\left(\mathrm{D}_{\mathrm{F}}\right)+\mathrm{d}\left(\mathrm{D}_{\mathrm{F}}\right)^{2}
$$

where, $a, b, c$ and $d$ are regression coefficients while, $\mathrm{L}_{F}$ and $\mathrm{D}_{\mathrm{F}}$ are the length and dosage of fiber reinforcement, respectively. Tables 4 and 5 respectively show the details of the regression analysis for FC and FM reinforcements. The best fit parabolic equations for the estimation of UCS of the reinforced expansive soil with FC and FM reinforcements are given below:

$$
\begin{aligned}
& U C S_{F i t_{-} F C_{-} 28}=2137.79-39.86\left(\mathrm{~L}_{\mathrm{FC}}\right)-1006.95\left(\mathrm{D}_{\mathrm{FC}}\right)+839.75\left(\mathrm{D}_{\mathrm{FC}}\right)^{2} \text { with } \mathrm{R}^{2}=0.973 \\
& U C S_{F i t_{-} F M_{-} 28}=2329.16-82.74\left(\mathrm{~L}_{\mathrm{FM}}\right)-1662.39\left(\mathrm{D}_{\mathrm{FM}}\right)+2688.31\left(\mathrm{D}_{\mathrm{FM}}\right)^{2} \text { with } \mathrm{R}^{2}=0.962 \\
& U C S_{F i t_{-} F C_{-} 360}=3804.46-45.07\left(\mathrm{~L}_{\mathrm{FC}}\right)-1959.61\left(\mathrm{D}_{\mathrm{FC}}\right)+876.81\left(\mathrm{D}_{\mathrm{FC}}\right)^{2} \text { with } \mathrm{R}^{2}=0.997 \\
& U C S_{F_{i t_{-} F M_{-} 360}}=3100.69-99.83\left(\mathrm{~L}_{\mathrm{FM}}\right)-1230.69\left(\mathrm{D}_{\mathrm{FM}}\right)+321.06\left(\mathrm{D}_{\mathrm{FM}}\right)^{2} \text { with } \mathrm{R}^{2}=0.952
\end{aligned}
$$

The statistical analysis presented in Tables 4 and 5 shows that the parabolic regression functions have relatively good fit to the experimental data measured for correlating the UCS and fiber volume.

\section{Limit State Function for UCS}

A limit state is a boundary between desired and undesired performance of a pavement constructed on treated expansive soils. This limit state is incorporated into pavement reliability analysis, which is concerned with the treatment of random variables. The soil in the present study can be used as a pavement material and its probability of failure $\left(\mathrm{P}_{\mathrm{f}}\right)$ is defined as follows 


$$
P_{f}=P\left(U C S<U C S_{\min }\right)=P\left(U C S-U C S_{\min }<0\right)=P\left(\frac{U C S}{U C S_{\min }}-1<0\right)
$$

where, $U C S_{\min }$ is the minimum specified UCS value to avoid subgrade failure. Subgrade UCS failure of compacted soil with lime treated soil, may be defined as the event of UCS less than the minimum specified UCS value (UCS $S_{\text {min }}$ ), over a design life of the pavement. Moreover, the limit state functions for the subgrade material failure for FC and FM reinforcements with curing periods of 28 and 360 days are given by

$$
\begin{aligned}
& g_{1}(x)=\frac{U C S_{F i t_{\_} F C_{-} 28}}{U C S_{\text {min }}}-1 \\
& g_{2}(x)=\frac{U C S_{F i t_{-} F C_{-} 360}}{U C S_{\text {min }}}-1 \\
& g_{3}(x)=\frac{U C S_{F i t_{-} F M_{-2} 28}}{U C S_{\text {min }}}-1 \\
& g_{4}(x)=\frac{U C S_{F i t_{-} F M_{-} 360}}{U C S_{\text {min }}}-1
\end{aligned}
$$

The TRA process iteratively carries out two optimizations: a design optimization in an original random space ( $X$ space) and a reliability analysis in an independent and standard normal random space ( $U$ - space). The general form of RBDO problem is formulated as follows: During the TRA process, a transformation between $X=\left\{L_{F C}, D_{F C}, U C S_{\min }\right\}$ and $U=\left\{\frac{L_{F C}-\mu_{L_{F C}}}{\sigma_{L_{F C}}}, \frac{D_{F C}-\mu_{D_{F C}}}{\sigma_{D_{F C}}}, \frac{U C S_{\min }-\mu_{U C S_{\min }}}{\sigma_{U C S_{\min }}}\right\}$ spaces at a design point must be carried out to estimate the probabilistic constraint. The parameters, $\mu_{L_{F C}}, \mu_{D_{F C}}$ and $\mu_{U C S_{\min }}$ are the mean values of $L_{F C}, D_{F C}, U C S_{\min }$ respectively. Moreover, $\sigma_{L_{F C}}, \sigma_{D_{F C}}$ and $\sigma_{U C S_{\min }}$ are the standard deviations of $L_{F C}, D_{F C}, U C S_{\min }$ respectively. The first-order probabilistic performance measure, is obtained from the optimization problem in $U$ space, as

Find $L_{F C}$ and $D_{F C}$ which $\left\{\begin{array}{lc}\text { minimizes } & g_{1}(u) \\ \text { subject to } & \sqrt{u^{\mathrm{T}} u}=\beta_{F C_{-} U C S_{-} 28}\end{array}\right.$

where $g_{1}(u)=0$ describes the failure surface in the $\mathrm{U}$-space. The nonlinear constrained optimization problem shown in Eq. (11) can be solved using the method of Lagrange multipliers. 


\section{Variability Associated with Random Parameters}

For evaluating the effect of uncertainty in the performance of subgrade material, uncertainty associated with length of fiber cast ( $L_{F C}$ ), length of FM ( $L_{F M}$ ), dosage of FC ( $D_{F C}$ ), dosage of FM ( $D_{F M}$ ) and minimum specified UCS ( $U C S_{\min }$ ) was represented by assigning mean and standard deviation in terms of coefficient of variation (COV) for each parameter. These mean and standard deviation values of material properties were chosen based on the range of values suggested in the literature (Sani et al., 2014). The statistics of the parameters chosen for design optimization are presented in Table 6. The values of $C O V$ pertaining to length of FC ( $\left.L_{F C}\right)$, length of FM ( $\left.L_{F M}\right)$, dosage of FC ( $\left.D_{F C}\right)$ and dosage of FM ( $\left.D_{F M}\right)$ are considered to be $5 \%$ as these parameters can be controlled. As suggested by Azzouz et al. (2008), the probability density functions corresponding to $L_{F C}, L_{F M}, D_{F C}$ and $D_{F M}$ are assumed to be normally distributed. For the stability against UCS failure, $U C S_{\min }$ of fiber reinforced soil is assumed to be more than or equal to $1103 \mathrm{kPa}$ in the present study. Based on the laboratory measured strength data, Sani et al. (2014) reported that the UCS samples are lognormally distributed with COV of $48.81 \%$. In addition, they considered the COV of $U C S_{\min }$ ranges between 10 and $100 \%$ for reliability analysis. However, in the present study, COV of $U C S_{\text {min }}$ is assumed to be ranging from 10 to $60 \%$ for the design purposes.

\section{Computation of Design Values of $L_{F C}, D_{F C}$ and $U C S_{\min }$ for a Target Reliability Index}

The design point $\left(L_{F C}, D_{F C}, U C S_{\text {min }}\right.$ ) corresponding to a given target reliability index $\left(\beta_{F C_{-} U C S_{-} 28}\right)$ can be expressed as (Basha and Babu, 2010)

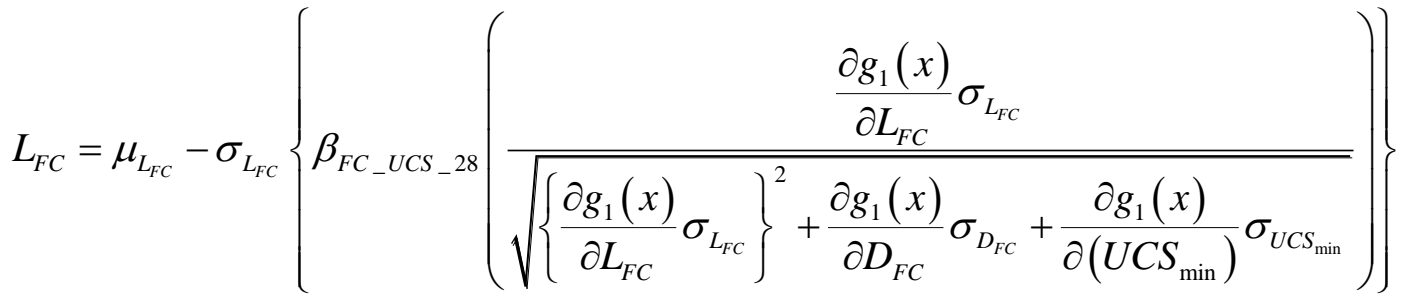

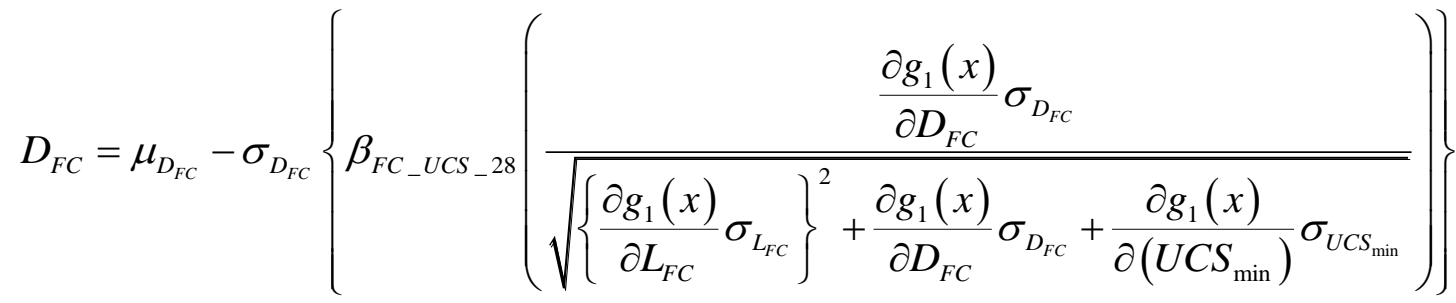

$$
U C S_{\min }=\mu_{U C S_{\min }}-\sigma_{U C S_{\min }}\left\{\beta_{F C_{-} U C S_{-} 28}\left(\frac{\frac{\partial g_{1}(x)}{\partial\left(U C S_{\min }\right)} \sigma_{U C S_{\min }}}{\sqrt{\left\{\frac{\partial g_{1}(x)}{\partial L_{F C}} \sigma_{L_{F C}}\right\}^{2}+\left\{\frac{\partial g_{1}(x)}{\partial D_{F C}} \sigma_{D_{F C}}\right\}^{2}+\left\{\frac{\partial g_{1}(x)}{\partial\left(U C S_{\min }\right)} \sigma_{U C S_{\min }}\right\}^{2}}}\right)\right\}
$$


As $U C S_{\min }$ is log-normally distributed, the parameters of the equivalent normal distribution, $\mu_{U C S_{\min }}^{N}$ and $\sigma_{U C S_{\min }}^{N}$ need to be computed using Rackwitz and Fiessler (1978) procedure. The algorithm to find the design values can be referred to Basha and Babu $(2010,2012)$. Similarly, the design values of $L_{F C}, L_{F M}, D_{F C}, D_{F M}$ and $U C S_{\text {min }}$ for targeted values of reliability indices, $\beta_{F C_{-} U C S_{-} 360}, \beta_{F M_{-} U C S_{-} 28}$ and $\beta_{F M_{-} U C S_{-} 360}$ can be computed using performance functions, $g_{2}(x), g_{3}(x)$ and $g_{4}(x)$, respectively. In the following sections, the influence of adding FC and FM reinforcement to blended expansive soil on the reliability indices against UCS strength failure are discussed in Figs. 6 to 10.

\title{
Effect of Variablilty on Strength Behavior of Treated Soil
}

\author{
Effect of Volume of Fiber Cast Reinforcement on $\beta_{U C S_{-} F C_{-} 28}$
}

The UCS of soil increases with the increase in cohesion and friction among its particles. The more the soil is compacted, the closer its particles come together, developing stronger cohesion among particles. The fiber reinforced soils supposed to increase the cohesion and friction among the composite and hence it is expected that the UCS would also increase. Reliability analysis has been performed with UCS value of sample which is cured for 28 days.

The results presented in Figs. 6(a)-(f) show the influence of increasing the volume of FC reinforcement by increasing its length and dosage on the magnitude of $\beta_{U C S_{-} F C_{-} 28}$. The results in Figs. 6(a)-(f) indicated that dosage of fiber plays a more important role in lime blended and treated expansive soils. It can be readily observed from Figs. 6(a)-(f) that for constant value of $L_{F C}$, the magnitude of reliability index, $\beta_{U C S_{-} F C_{-} 28}$ shows reduction with increase in the dosage of fiber cast reinforcement $\left(D_{F C}\right)$ from 0.05 to $0.45 \%$. It appears that more dosage of FC reinforcement reduces the UCS value. This reduction is attributed to the fact that smooth fibers do not allow the soil to compact when reinforced. In addition, the fibers reduce the cohesion of the soil by increasing the distance between particles. The increase in friction induced by the fibers does not compensate this loss in cohesion. Figs. 6(a)-(f) reveals that the axial stress at the failure of fiber reinforced soil does not appreciably reduce with an increase in the fiber content beyond $0.45 \%$ for $\mathrm{COV}$ of $\mathrm{UCS}_{\min }$ ranging from 10 to $60 \%$. This is due to the fact that an increase in fiber content beyond $0.45 \%$ induces a marginal change in cohesion and friction of treated soils.

\section{Effect of Curing Period on Reliability Index}

The experimental results show that for all 360 days cured sample gives highest UCS to 28 days cured sample as the hydration occurs during the curing period due to the presence of cementitious materials in lime. The results presented in Fig. 7 show the influence of curing period on reliability index against UCS failure for $U C S_{\min }=1103 \mathrm{kPa}, D_{F C}$ $=0.4 \%, \mathrm{COV}$ of $L_{F C}=5 \%, \mathrm{COV}$ of $D_{F C}=5 \%, D_{F M}=0.4 \%, \mathrm{COV}$ of $L_{F M}=5 \%, \mathrm{COV}$ of $D_{F M}=5 \%$ and COV of $U C S_{\min }=20 \%$. It may be observed from Fig. 7 that for a constant value of length of FC reinforcement $\left(L_{F C}\right)=$ $6 \mathrm{~mm}$, when the curing period increased from 28 to 360 days, there is a significant increase in the magnitude of reliability index from 2.1 (i.e. $\beta_{\mathrm{UCS} \_F C_{-} 28}$ ) to 4.9 (i.e. $\beta_{\mathrm{UCS} \_F C \_360}$ ). There is a $133.33 \%$ increase in reliability index due to effect of cementation. Similar observation can be made from Fig. 7 that for a constant value of FM reinforcement $\left(L_{F M}\right)=6 \mathrm{~mm}$, the reliability index increases from 1.9 (i.e. $\left.\beta_{\text {UCS_FM_28 }}\right)$ to 3.25 (i.e. $\beta_{\text {UCS_FM_360 }}$ ) when the curing period increased from 28 to 360 days. The percentage increase in reliability index is $65.81 \%$ when the expansive soil is treated with FM reinforcement. 


\section{Optimum Length and Dosage of FC Reinforcement for 28 and 360 Days Curing Period}

Figs. 6(a) to 6(f) report the optimum values of length ( $L_{F C}$ ) and dosage ( $D_{F C}$ ) of FC reinforcement when the fiber reinforced soil samples are cured for 28 days for different target values of reliability indices ( $\left.\beta_{\mathrm{UCS}_{-} F C_{-} 28}\right)$ for $C O \mathrm{~V}$ of $U C S_{\min }=10,20,30,40,50$ and $60 \%$ respectively and for the typical values chosen in the present study. Similar to the results presented in Fig. 6, Figs. 8(a) to 8(e) give the optimum values of length ( $L_{F C}$ ) and dosage ( $D_{F C}$ ) of FC reinforcement when the fiber reinforced soil samples are cured for 360 days for various values of $\beta_{\text {UCS_FC_360 }}$. Based on the results of Figs. 6 and 8, it is found that the optimum values of $L_{F C}$ and $D_{F C}$ required for the subgrade material stability in terms of UCS strength depends on the COV of $U C S_{\min }$. It is observed that adding 0.05 to $0.6 \%$ FC reinforcements of length up to $12 \mathrm{~mm}$ enhances the UCS strength significantly and consequently increase the safety levels (i.e. $\beta_{\mathrm{UCS}_{-} F C_{2} 28}$ and $\beta_{\mathrm{UCS}_{-} F C_{-} 360}$ ) of pavement subgrade material. Moreover, it can be noted from Figs. 6 and 8 that when there is a high degree of variability associated with $U C S_{\min }$ i.e. $C O V$ of $U C S_{\min } \geq 30 \%$ for 28 days curing period and $C O V$ of $U C S_{\text {min }} \geq 50 \%$ for 360 days curing period, adding $12 \mathrm{~mm}$ length fibers with 0.05 to $0.6 \%$ fiber content is not adequate to get the acceptable performance of the subgrade material as both the reliability indices, $\beta_{C B R_{-} F C} \leq 3.0$ and $\beta_{C B R_{-} F M} \leq 3.0$.

Effect of Volume of FM Reinforcement on Reliability Indices, $\beta_{U C S_{-} F M_{-} 28} \underline{\text { and }} \beta_{U C S_{-} F M_{-} 360}$

Figs. 9(a) to 9(f) show the influence of increasing the volume of FM reinforcement by increasing its length and dosage on the magnitude of $\beta_{U C S_{-} F M_{-} 28}$. Figs. 9(a) to 9(f) report the optimum values of length ( $L_{F M}$ ) and dosage ( $D_{F M}$ ) of fiber mesh reinforcement when the fiber reinforced soil samples are cured for 28 days for $C O V$ of $U C S_{\min }=10$, $20,30,40,50$ and $60 \%$, respectively. It may be pertinent to note that the magnitude of reliability index ( $\beta_{U C S_{-} F M_{-} 28}$ ) decreases with the increase in FM content up to $0.3 \%$. However, the reliability index, $\beta_{U C S} S_{-} M_{-} 360$ marginally increases when the FM content increases beyond $0.3 \%$. This increment can be attributed to fact that the rough fibers reduce the cohesion of the soil by increasing the distance between particles. However, the increase in friction induced by the rough fibers does compensate the loss in cohesion. The results presented in Figs. 10(a) to (e) give the optimum values of length ( $L_{F M}$ ) and dosage ( $D_{F M}$ ) of FM reinforcement for various values of $\beta_{\text {UCS_FM_360 }}$ when the fiber reinforced soil samples are cured for 360 days. The observed trends of Figs. 10(a) to 10(e) are similar to those presented in Figs. 6 and 8.

\section{Summary and Conclusions}

The influence of length and dosage of two types of fibers, FC and FM, on the performance of lime stabilized soils has been investigated. The UCS was used as a performance indicator and a curing period up to 360 days was employed in case of lime-stabilized fiber reinforced soils. Secant moduli (50\% peak strength) were computed relying on stressstrain curves obtained from UCS data for all possible fiber parameters (length, dosage and type). A target reliability based design optimization procedure that considers uncertainties associated with minimum UCS of treated soil, length and dosage of FC and FM fiber reinforcement is illustrated. It is demonstrated that the proposed approach is capable of handling variability associated with UCS and producing subgrade materials of uniform reliability. Additionally, the 
length and dosage of FC and FM fiber reinforcement developed in this study considering the COV of UCS min $_{\text {, may be }}$ used to support adaptation to enable inclusion in standard codal specifications. The main findings of the present investigation are as follows:

1. UCS behavior is directly dependent on the nature and type of fiber. FM fibers with extended protrusions have distinct surface morphological advantage over FC type fibers enabling them in mobilizing higher friction levels.

2. For FC fibers, with increase in fiber dosage from $0.2 \%$ to $0.6 \%$, the UCS values reduced by $32 \%$ and $39 \%$ for 6 $\mathrm{mm}$ and $12 \mathrm{~mm}$ lengths, respectively. On the contrary, for FM fibers, for a similar change in fiber amount, the UCS values for samples mixed with $6 \mathrm{~mm}$ fiber length reduced by $30 \%$ while those of $12 \mathrm{~mm}$ fiber lengths showed an increase of $12 \%$.

3. The combined addition of lime and fiber has a significant effect on the rate of gain of UCS. These values notably increased with curing periods up to 60 days and the rate of gain in UCS at higher curing periods (from 60 to 180 days) proceeds at a slower rate.

4. The secant moduli values increased with curing periods up to 60 days and stayed approximately constant until 180 days and this increase is proportional to the increase in UCS values.

5. The mean values of the lengths and dosage of FC and FM reinforcements are important design variables in fiber reinforced treated expansive soils that influence the pavement subgrade stability to the large extent.

6. The variability associated with the minimum specified value of UCS (UCS $\left.S_{\min }\right)$ have significant influence on the reliability index against UCS strength failure mode.

7. The reliability index against UCS failure of fiber reinforced soil does not appreciably reduce with an increase in the fiber content beyond $0.45 \%$ for all values of COV of $\mathrm{UCS}_{\min }$.

8. An important observation from the present study is that the percentage increase in reliability indices of pavement subgrade material which is treated with FC and FM reinforcements are $133.33 \%$ and $65.81 \%$ when the samples are cured for 28 and 360 days, respectively.

9. The adequate lengths and dosage of FC and FM reinforcements should be provided for a specified target value of reliability index when COV of $U C S_{\text {min }}$ increases from 10 to $60 \%$. Further, addition of $0.6 \%$ of FC and FM reinforcements of lengths up to $12 \mathrm{~mm}$ is inadequate to get the acceptable performance in terms of UCS strength when $C O V$ of $U C S_{\min } \geq 30 \%$ for 28 days curing period and $C O V$ of $U C S_{\min } \geq 50 \%$ for 360 days curing period.

\section{Acknowledgements}

This project was funded by the National Plan for Science, Technology and Innovation (MAARIFAH), King Abdulaziz City for Science and Technology, Kingdom of Saudi Arabia, Award Number (11BUI1489-02). The authors would like to thank the reviewers for their constructive comments, which helped the cause of the manuscript.

\section{References}

AASHTO (1993). Guide for Design of Pavement Structures, American Association of State Highway and Transportation Officials, Washington, D.C.

Abu-Sharkh, B.F., and Hamid, H. (2004). Degradation study of date palm fibre/polypropylene composites in natural and artificial weathering: mechanical and thermal analysis. Polym. Degrada. Stabi., 85(3), 967-973

Ahmad, F., Bateni, F., and Azmi, M. (2010). "Performance evaluation of silty sand reinforced with fibers." Geotext. Geomembr., 28(1), 93-99.

Anggraini, V., Asadi, A., Huat, B.B.K., and Nahazanan, H. (2015). "Effects of coir fibers on tensile and compressive strength of lime treated soft soil.” Measurement., 59, 372-381.

ASTM C117-13 (2013). Standard Test Methods for determining the amount of material finer than 75- $\mu \mathrm{m}$ (No. 200) sieve in soils by washing. ASTM International, West Conshohocken, PA.

ASTM D1993-03 (2013) el. Standard Test Methods for precipitated silica - surface area by multipoint BET nitrogen adsorption. ASTM International, West Conshohocken, PA. 
This is an author-produced, peer-reviewed version of this article. The final, definitive version of this document can be found online at Journal of Materials in Civil Engineering, published by American Society of Civil Engineers. Copyright restrictions may apply. doi: 10.1061/(ASCE)MT.1943-5533.0001835

ASTM D2166M-13 (2013). Standard Test Method for Unconfined Compressive Strength of Cohesive Soil. ASTM West Conshohocken, PA.

ASTM D2487-11 (2011). Standard Practice for Classification of Soils for Engineering Purposes (Unified Soil Classification System). ASTM International, West Conshohocken, PA.

ASTM D4318-10el (2010). Standard Test Methods for liquid limit, plastic limit and plasticity index of soils. ASTM International, West Conshohocken, PA.

ASTM D4943-08 (2008). Standard Test Methods for shrinkage factors of soils by the wax method. ASTM International, West Conshohocken, PA.

ASTM D4959-16 (2016). Standard Test Method for Determination of Water Content of Soil by Direct Heating. ASTM West Conshohocken, PA.

ASTM D4972-13 (2013). Standard Test Method for pH of Soils. ASTM International, West Conshohocken, PA.

ASTM D698-07e1 (2007). Standard Test Methods for Laboratory Compaction Characteristics of Soil Using Standard Effort. West Conshohocken, PA.

ASTM D854-14 (2014). Standard Test Methods for specific gravity of soil solids by water pycnometer. ASTM International, West Conshohocken, PA.

Azzouz, B., Hassen M. B., Sakli, F. (2008). Adjustment of Cotton Fiber Length by the Statistical Normal Distribution: Application to Binary Blends. J. Engineered Fibers and Fabrics, 3(3), 35-46.

Babu, G.L.S., and Vasudevan, A.K. (2008). "Strength and Stiffness Response of Coir Fiber-Reinforced Tropical Soil." J. Mater. Civ. Eng., 20(9), 571-577.

Basha, B.M., and Babu, G.L.S. (2010). "Optimum design for external seismic stability of geosynthetic reinforced soil walls: A reliability based approach.” J. Geotech. Geoenv. Engrg., 136(6), 797-812.

Basha, B.M., and Babu, G.L.S. (2012). "Target reliability based optimization for internal seismic stability of reinforced soil structures". Geotechnique, 62(1), 55-68.

Cai, Y., Shi, B., Ng, C.W.W., and Tang, C. (2006). "Effect of polypropylene fibre and lime admixture on engineering properties of clayey soil." Engrg. Geol., 87(3-4), 230-240.

Chittoori, B., Puppala, A., Pedarla, A., and Vanga, D. (2014). "Durability Studies on Native Soil-based Controlled Low Strength materials. Ground Improvement and Geosynthetics". Geotechnical Special Publication No. 238, 249-257.

Chittoori, B.S., Puppala, A.J., Saride, S., Nazarian, S., and Hoyos, L.R. (2009). "Durability Studies of lime stabilized clayey soils". In the Proc. of $17^{\text {th }}$ International Conference on Soil Mechanics and Geotechnical Engineering, ICMGE 2009, 2208-2211.

Consoli, N.C., Bassani, M.A.A., and Festugato, L. (2010). Effect of fiber-reinforcement on the strength of cemented soils. Geotex. Geomem., 28, 344-351.

Consoli, N.C., De Moraes, R.R., and Festugato, L. (2013). "Variables controlling strength of fibre-reinforced cemented soils". Grou. Impro., 166(4), 221-232.

Consoli, N.C., Lopes, Jr. L.S., Foppa, D., and Heineck, K.S. (2009). "Key parameters dictating strength of lime/cement-treated soil". Proceed. Inst. Civ. Engrs. - Geotech. Engrg., 162(2), 111-118.

Consoli, N.C., Zortéa, F., De Souza, M., and Festugato, L. (2011). Studies on the dosage of fiber-reinforced cemented soils. J. Mater. Civ. Engrg., 23(12), 1624-1632.

Correia, A.A.S., Oliveira, P.J.V., and Custódio, D.G. (2015). "Effect of polypropylene fibres on the compressive and tensile strength of a soft soil, artificially stabilised with binders". Geotex. Geomem., 43(2), 97-106.

Eades, J.L., and Grim, R.E. (1960). "Reaction of Hydrated Lime with Pure Clay Minerals in Soil Stabilization." Highway Research Board, Washington, D.C. Bulletin, 262, 51-63.

Gray, D. H. (1970). "Role of woody vegetation in reinforcing soils and stabilizing slopes." Proc., Symp. on Soil Reinforcement and Stabilizing Techniques, Sydney, Australia, 253-306.

Gray, D. H., and Maher, M. H. (1989). "Admixture stabilization of sand with discrete randomly distributed fibers." Proc., XII Int. Conf. on Soil Mechanics and Foundation Engineering, Vol. 2, Rio de Janeiro, Brazil, 13631366.

Gromko, G. J. (1974). Review of expansive soils. J. of the Geotech. Engrg. Div., 100(6), 667-687.

Jones, D.E. and Holtz, W.G. (1973). Expansive soils - the hidden disaster. Civil Eng., ASCE, New York, NY pp 8789, Aug. 1973.

Kumar, A., Walia, B.S., and Mohan, J. (2006). Compressive Strength of fiber reinforced highly compressible clay. Cons. Build. Mater., 20, 1063-1068.

Maher, M.H, Ho, Y.C. (1994). Mechanical-properties of kaolinite fiber soil composite. J Geotech Engrg., 120(8), 1381-1393. 
Marandi, S.M., Bagheripour, M.H., Rahgozar, R., and Zare, H. (2008). Strength and ductility of randomly distributed palm fibers reinforced silty-sand soils. Amer. J. App. Phy., 5(3), 209-220.

Moghal A.A.B., Dafalla, M.A., Elkady, T.Y., and Al-Shamrani, M.A., (2015c). "Lime Leachability Studies on Treated Expansive Semi-arid Soil”. Intl. J. Geomate., 9(2), 1467-1471.

Moghal, A.A.B., Al-Obaid, A.K., Al-Refeai, T.O., and Al-Shamrani, M.A. (2015a). "Compressibility and Durability Characteristics of Lime Treated Expansive Semiarid Soils." J. of Test. and Eval., 43(2), 255-263.

Moghal, A.A.B., Al-Obaid, A.K., and Al-Refeai, T.O. (2014). "Effect of Accelerated Loading on the Compressibility Characteristics of Lime Treated Semi Arid Soils." J. Mater. Civ. Engrg., 26(5), 1009-1016.

Moghal, A.A.B., Dafalla, M.A., Elkady, T.Y., and Al-Shamrani, M.A. (2015b). "Lime Leachability Studies on Treated Expansive Semi-arid Soil." Intl. J. Geomate, 9(2), 1467-1471.

Nataraj, M.S., and McManis K.L. (1997). "Strength and deformation properties of soils reinforced with fibrillated fibers." Geosyn. Intl., 4(1), 65-79

National Lime Association. (2004) "Lime-Treated Soil Construction Manual: Lime Stabilization and Lime Modification." Bulletin 326, National Lime Association, VA.

Ozkul, Z.H., and Baykal, G. (2006). "Shear strength of clay with rubber fiber inclusions." Geosyn. Intnl., 13(5), 173-180.

Petry, T. M., and Armstrong, J. C. (1989). Stabilization of expansive clay soils. Transportation Research Record, (1219).

Petry, T.M. and Little, D.N. (2002). "Review of Stabilization of Clays and Expansive Soils in Pavements and Lightly Loaded Structures-History, Practice, and Future." J. Mater. Civ. Engrg., 14(6), 447-460.

Qu, J., and Zhao, D. (2016). "Stabilising the cohesive soil with palm fibre sheath strip." Road Mat. and Pav. Des., 17(1), 87-103.

Rackwitz, R., and Fiessler, B. (1978). "Structural reliability under combined random load sequences." Comp. and Struct, 9: $489-494$.

Sani, J.E., Bello, A.O., and Nwadiogbu, C. P. (2014). "Reliability estimate of strength characteristics of black cotton soil pavement sub-base stabilized with bagasse ash and cement kiln dust." Civ. and Env. Res., 6(11), 115 135.

Sivapullaiah, P.V., and Moghal, A.A.B. (2011). "Role of Gypsum in the Strength Development of Fly Ashes with Lime". J. Mater. Civ. Engrg., 23(2), 197-206.

Tang, C., Wang, D., Cui, Y., Shi, B., and Li, J. (2016). "Tensile Strength of Fiber-Reinforced Soil." J. Mater. Civ. Eng., 10.1061/(ASCE)MT.1943-5533.0001546

Tang, C.S., Shi, B., Gao, W., Chen, F., and Cai, Y. (2007). "Strength and mechanical behavior of short polypropylene fiber reinforced and cement stabilized clayey soil." Geotex. Geomem., 25(3), 194-202.

Tex-107-E (1999). Test Procedure for Determining the Bar Linear Shrinkage of Soils. Texas Department of Transportation Document, Construction Division, Austin, Texas.

Vanapalli, S. K., \& Adem, H. H. (2013). Estimation of the 1-D heave of a natural expansive soil deposit with a light structure using the modulus of elasticity based method, Advances in Unsaturated soils, Edited by Caicedo, B., Murillo, C., Hoyos, L., Colmenares, J. E., and Berdugo, I. R., Taylor and Francis, 101-114.

Zhu, H. H., Zhang, C. C., Tang, C. S., Shi, B., and Wang, B. J. (2014). "Modeling the pullout behavior of short fiber in reinforced soil." Geotext. Geomembr., 42(4), 329-338.

\section{List of Tables}

Table 1. Physico-Chemical properties of soil used in this research

Table 2. Physico-Chemical properties of fibers used in this research

Table 3. Variation of Maximum Dry Density and Optimum Moisture Content with different types of fiber material at their respective dosages

Table 4. The proposed best fit parabolic equation for UCS ( $U C S_{F i t_{-} F C_{-} 28}$ ) with FC fibers measured after 28 and 360 days curing period 
Table 5. The proposed best fit parabolic equation for UCS ( $U C S_{F i t_{-} F M_{-} 28}$ ) with FM fiber measured after 28 and 360 days curing period

Table 6. Statistics of random input parameters

\section{List of Figures}

Figure 1 Fibers used in the study and their Scanning Electron Micrographs

Figure 2 Variation of UCS strength with curing period for soil treated with Fiber Cast and Fiber Mesh

Figure 3 Variation of UCS data with amount and length of fibers with lime treatments at 28 days curing period

Figure 4 Variation of secant modulus with curing period for fiber cast and fiber mesh

Figure 5 Effect of fiber dosage and length on the secant modulus of soil

Figure 6 Variation of $\beta_{\text {UCS_FC_28 }}$ and $L_{F C}$ with $D_{F C}$ with fiber cast for COV of $U C S_{\text {min }}$ (a). $10 \%$ (b). $20 \%$ (c). $30 \%$ (d). $40 \%$ (e). $50 \%$ and (f). $60 \%$

Figure 7 Effect of curing period on reliability indices with fiber cast and fiber mesh

Figure 8 Variation of $\beta_{\text {UCS_FC_360 }}$ and $L_{F C}$ with $D_{F C}$ with fiber cast for COV of $U C S_{\text {min }}$ (a). $20 \%$ (b). $30 \%$ (c). $40 \%$ (d). $50 \%$ and (e). $60 \%$

Figure 9 Variation of $\beta_{\text {UCS_FM_28 }}$ and $L_{F M}$ with $D_{F M}$ for fiber mesh with COV of $U C S_{\text {min }}$ (a). $10 \%$ (b). $20 \%$ (c). $30 \%$ (d). $40 \%$ (e). $50 \%$ and (f). $60 \%$

Figure 10 Variation of $\beta_{\text {UCS_FM_360 }}$ and $L_{F M}$ with $D_{F M}$ for fiber mesh with COV of $U C S_{\min }$ (a). $20 \%$ (b). $30 \%$ (c). $40 \%$ (d). $50 \%$ and (e). $60 \%$ 